\title{
Shoulder tendinitis and osteoarthrosis of the acromioclavicular joint and their relation to sports
}

\section{B. Stenlund MD}

The Construction Industry's Organization for Working Environment, Safety and Health, Stockholm, Sweden and the Departments of Orthopaedics and Occupational Health, Karolinska Hospital, Stockholm, Sweden

\begin{abstract}
A sample of 207 men from the construction industry was studied using an epidemiological technique of crosssectional design to investigate if sport activities involving the arms increase the risk of developing shoulder tendinitis or osteoarthrosis of the acromioclavicular joint. The relative risk for shoulder tendinitis was estimated to be 9.5 on the right side, and 4.9 on the left side for a lifetime of sport activity exceeding $8399 \mathrm{~h}$. Subjects who reported both extremely high physical load from work and from sports had an estimated relative risk for signs of shoulder tendinitis of 5.9 on the right side and 10.4 on the left side. High sport activity yielded relative risks of 4.6 on the right side and 2.8 on the left side for osteoarthrosis of the acromioclavicular joint. The combination of high activity in sports and high exposure to load lifted during work yielded relative risks for osteoarthrosis of the acromioclavicular joint of $\mathbf{1 2 . 5}$ on the right side and 6.7 on the left side. There seems to be an increased risk for shoulder tendinitis and acromioclavicular osteoarthrosis for subjects who have been extremely active in sports, and an even higher risk for those who have been extremely active in sports and also report a high exposure to load lifted during work.
\end{abstract}

Keywords: Rotator cuff, biceps, osteoarthrosis (osteoarthritis), clavicle, construction industry

Sports that involve the arms such as handball, ice-hockey, skiing and weightlifting cause stress and strain to the shoulders, in many ways comparable to that of heavy manual work. Kennedy and Hawkins ${ }^{1}$ for example, have reported on swimmer's shoulder and several authors have reported on baseball pitching and other sport activities as causes for injury to the shoulder muscles and tendons $\mathrm{s}^{2-6}$. It is possible that long-term exposure to sports involving the arms could result in increased risks for shoulder tendinitis or osteoarthrosis of the acromioclavicular joint, but epidemiological methods have previously not been used for risk evaluation of sports in relation to musculoskeletal complaints in the shoulders.

Stress and strain in the workplace are risk factors for shoulder disorders ${ }^{7,8}$ and in heavy manual work

Address for correspondence: Berndt Stenlund, Bygghälsan, Electrum/216, S-164 40, Sweden

(C) 1993 Butterworth-Heinemann Ltd 0306-3674/93/020125-06 and work involving vibrating tools there is a two- to three-fold increased risk for shoulder tendinitis and osteoarthrosis of the acromioclavicular joint ${ }^{8,9}$.

The aim of this study was to investigate whether long-term exposure to sports involving the arms increases the risk of shoulder tendinitis or osteoarthrosis of the acromioclavicular joint and if heavy work in addition to sports involving the arms further increases that risk.

\section{Subjects and methods}

The source population was drawn from construction industry workers in the Stockholm region and constituted three subgroups: bricklayers, rockblasters and foremen. There were only 75 registered rockblasters in the union files for the Stockholm area. All of these rockblasters were selected and 75 bricklayers and $\mathbf{1 1 0}$ foremen were randomly selected from the local union files to participate in the study. Nineteen bricklayers, 20 rockblasters and 13 foremen did not wish to participate or were unable to participate since they lived in another part of the country or abroad. One bricklayer was excluded from the investigation because of language difficulties. One of the bricklayers had worked for 18 years as a foreman and the last 2 years as a bricklayer and was consequently categorized as a foreman. Thus the persons under study finally comprised 54 bricklayers, 55 rockblasters and 98 foremen.

The mean age was 50.2 for bricklayers, 51.8 for rockblasters and 45.8 for foremen. Dexterity was unevenly distributed between working groups. There were more left-handed and ambidextrous bricklayers and rockblasters than there were foremen.

A summary of the background variables (age, dexterity, smoking habits and citizenship) is presented in Tables 1 and 2.

The investigation was conducted in three different parts: exposure assessment; clinical examination; and radiographic examination.

A protocol was developed to record estimated life hours of sport activities, load lifted during working life, hours of vibration exposure, smoking habits, dexterity, job titles, years of manual work, and citizenship. The protocol was used by a specially trained nurse who interviewed the participants.

The sport activities were summarized on an annual basis. Common Swedish sport activities that engaged 
Table 1. Background variables and exposures

\begin{tabular}{llll}
\hline Variables & \multicolumn{1}{c}{ Bricklayers } & \multicolumn{1}{c}{ Rockblasters } \\
\hline Age & $50.2(11.4)(26-68)$ & $51.8(11.6)(33-70)$ & Foremen \\
Sport activities $(h)$ & $2173(6057)(0-36000)$ & $2760(5909)(0-28800)$ & $35.8(10.2)(27-65)$ \\
Load lifted (tonnes) & $29437(18580)(1144-84034)$ & $33210(23572)(3388-123082)$ & $2261(3975)(0-24840)$ \\
Years of manual work & $30.8(11.2)(2-52)$ & $30.8(12.0)(9-58)$ & $4.9(7.1)(0-24)$ \\
\hline
\end{tabular}

Figures are mean(s.d.) (range)

one or both arms were included in the protocol and were: pistol shooting; handball; ice-hockey; golf; tennis; badminton; squash; skiing; swimming; cycling; rallying; weightlifting; wrestling; gymnastics; and a miscellaneous category including all other arm sport activities not specified in the list (e.g. boxing, goalkeeper in soccer, javelin throwing, discus throwing and cycling). Each activity was reported as hours per day, per week, and per year and the hours were summarized. The reported hours of each sport activity for the different job titles is presented in Table 3. The sport activity hours were classified into three classes 0-5279 life hours, 5280-8399 life hours and $>8399$ life hours. The value $\mathbf{5 2 8 0}$ was chosen since it was the median value for all the subjects, the higher value, 8399 , was chosen since $5 \%$ of the participants reported having been active for more than $8399 \mathrm{~h}$ which represents a little more than $8 \mathrm{~h}$ a week every single week for 20 years. Exposure to more than 8399 life hours of sports was considered in the calculations to be a high exposure to sport, whereas less than 5280 reported life hours was considered to be a low exposure to sport.

Load lifted during work was summarized on an annual basis. The participant calculated how many days he had worked per year, how many loads he

Table 2. Background variables and frequencies of outcome variables in compared working groups

\begin{tabular}{|c|c|c|c|}
\hline \multirow[t]{2}{*}{ Variables } & $\begin{array}{l}\text { Bricklayers } \\
\quad(\mathrm{n}=54)\end{array}$ & $\begin{array}{l}\text { Rockblasters } \\
(\mathrm{n}=55)\end{array}$ & $\begin{array}{l}\text { Foremen } \\
(n=98)\end{array}$ \\
\hline & No. & No. & No. \\
\hline Right-handed & $44(81.5)$ & $43(78.2)$ & $83(84.7)$ \\
\hline Left-handed & $2(3.7)$ & $3(5.5)$ & $1(1.0)$ \\
\hline Ambidextrous & $8(14.8)$ & $9(16.4)$ & $14(14.3)$ \\
\hline Smokers & $24(44.4)$ & $23(41.8)$ & $28(28.6)$ \\
\hline Non-smokers & $9(16.7)$ & $11(20.0)$ & $36(36.7)$ \\
\hline Previous smokers & $21(38.9)$ & $21(38.2)$ & $34(34.7)$ \\
\hline Swedish citizenship & $48(88.9)$ & $50(90.9)$ & $86(87.8)$ \\
\hline Other citizenship & $6(11.1)$ & $5(9.1)$ & $12(12.2)$ \\
\hline \multicolumn{4}{|l|}{ Signs of tendinitis } \\
\hline \multicolumn{2}{|l|}{ Signs of tendinitis } & $22(40.0)$ & $17(17.1)$ \\
\hline \multicolumn{4}{|c|}{$\begin{array}{l}\text { Clinical and radiological } \\
\text { signs of osteoarthrosis* }\end{array}$} \\
\hline Left AC-joint & $4(7.4)$ & $7(12.7)$ & $2(2.0)$ \\
\hline Right $\mathrm{AC}$-joint & $9(16.7)$ & $16(29.1)$ & $3(3.1)$ \\
\hline
\end{tabular}

Numbers in parentheses are percentages; $\mathrm{AC}$, acromioclavicular; * Positive radiographic signs of osteoarthrosis of the acromioclavicular joint in combination with positive pain reaction to forced adduction of the arm had lifted per day and their weight, e.g. weight of a brick and of the trowel and mortar together is $3.5 \mathrm{~kg}$; a jack hammer weighs $47.2-50.7 \mathrm{~kg}$. Rockblasters also lift rocks of different weights, and these loads were also estimated and taken into account.

Load lifted during work was categorized into one of three classes: 0-709; 710-25999; and >25999 tonnes. The limits 710 and 26000 tonnes were chosen since they represented the median values for the foremen (710 tonnes) and for the bricklayers and rockblasters (26000 tonnes). The value 710 tonnes corresponds to the lifting of $19.7 \mathrm{~kg} \mathrm{~h}^{-1}$ for $8 \mathrm{~h}$ a day, 225 days a year for 20 years. In the analyses exposure to more than 25999 tonnes was considered to be a high exposure and exposure to less than 710 tonnes was considered to be a low exposure.

Table 3. Reported hours of sports that engage arms, for the whole group and for each job title

\begin{tabular}{|c|c|c|c|c|}
\hline & Bricklayers & Rockblasters & Foremen & All \\
\hline Pistol-shooting & $\begin{array}{c}33.0 \\
(0-1280)\end{array}$ & $\begin{array}{c}96.5 \\
(0-4200)\end{array}$ & $\begin{array}{l}56.4 \\
(0-3640)\end{array}$ & $\begin{array}{c}60.9 \\
(0-4200)\end{array}$ \\
\hline Handball & $\begin{array}{c}35.1 \\
(0-1200)\end{array}$ & $\begin{array}{c}48.0 \\
(0-1440)\end{array}$ & $\begin{array}{l}60.6 \\
(0-2080)\end{array}$ & $\begin{array}{l}50.6 \\
(0-2080)\end{array}$ \\
\hline Ice-hockey & $\begin{array}{l}1295.6 \\
(0-36000)\end{array}$ & $\begin{array}{l}452.4 \\
(0-21600)\end{array}$ & $\begin{array}{l}259.3 \\
(0-2880)\end{array}$ & $\begin{array}{l}580.9 \\
(0-36000)\end{array}$ \\
\hline Golf & 0 & 0 & $\begin{array}{c}21.7 \\
(0-864)\end{array}$ & $\begin{array}{c}10.3 \\
(0-864)\end{array}$ \\
\hline Tennis & 0 & ${ }^{0}$ & $\begin{array}{l}152.0 \\
(0-9464)\end{array}$ & $\begin{array}{l}75.1 \\
(0-9464)\end{array}$ \\
\hline Badminton & 0 & $\begin{array}{c}40.5 \\
(0-2160)\end{array}$ & $\begin{array}{c}53.8 \\
(0-960)\end{array}$ & $\begin{array}{l}36.2 \\
(0-2160)\end{array}$ \\
\hline Squash & $\begin{array}{c}5.6 \\
(0-300)\end{array}$ & 0 & $\begin{array}{l}30.2 \\
(0-1312)\end{array}$ & $\begin{array}{l}15.7 \\
(0-1312)\end{array}$ \\
\hline Skiing & $\begin{array}{c}274.9 \\
(0-4800)\end{array}$ & $\begin{array}{c}450.0 \\
(0-7672)\end{array}$ & $\begin{array}{l}354.7 \\
(0-7650)\end{array}$ & $\begin{array}{l}359.2 \\
(0-7672)\end{array}$ \\
\hline Swimming & $\begin{array}{c}25.9 \\
(0-1400)\end{array}$ & 0 & $\begin{array}{c}48.0 \\
(0-1264)\end{array}$ & $\begin{array}{l}29.5 \\
(0-1400)\end{array}$ \\
\hline Motorcycling & 0 & $\begin{array}{c}9.5 \\
(0-520)\end{array}$ & $\begin{array}{l}26.7 \\
(0-1250)\end{array}$ & $\begin{array}{l}15.2 \\
(0-1250)\end{array}$ \\
\hline Rally & ${ }^{0}$ & ${ }^{0}$ & $\begin{array}{c}6.1 \\
(0-600)\end{array}$ & $\begin{array}{c}2.9 \\
(0-600)\end{array}$ \\
\hline Weightlifting & $\begin{array}{c}95.6 \\
(0-3360)\end{array}$ & $\begin{array}{c}206.7 \\
(0-7620)\end{array}$ & $\begin{array}{l}82.8 \\
(0-1920)\end{array}$ & $\begin{array}{l}119.0 \\
(0-7620)\end{array}$ \\
\hline Wrestling & $\begin{array}{c}79.0 \\
(0-1500)\end{array}$ & $\begin{array}{c}171.1 \\
(0-9000)\end{array}$ & $\begin{array}{c}2.9 \\
(0-144)\end{array}$ & $\begin{array}{c}67.4 \\
(0-9000)\end{array}$ \\
\hline Gymnastics & $\begin{array}{c}22.2 \\
(0-1200)\end{array}$ & $\begin{array}{c}67.2 \\
(0-3650)\end{array}$ & $\begin{array}{c}29.0 \\
(0-2400)\end{array}$ & $\begin{array}{l}37.4 \\
(0-3650)\end{array}$ \\
\hline Miscellaneous* & $\begin{array}{c}295.1 \\
(0-7200)\end{array}$ & $\begin{array}{l}1218.6 \\
(0-28800)\end{array}$ & $\begin{array}{l}143.4 \\
(0-5280)\end{array}$ & $\begin{array}{l}468.6 \\
(0-28800)\end{array}$ \\
\hline
\end{tabular}

Values are mean (range)

* Boxing, goalkeeping in soccer, javelin throwing, discus throwing and biking 
The different exposures to sports and work were analysed as: (1) sport activity hours during life; (2) sport activity hours in combination with the sum of load lifted during working years.

Dexterity was categorized as right-handed, lefthanded or ambidextrous. The left-handed and ambidextrous were put together in one group in the analyses since few were left-handed and most of the ambidextrous workers had been left-handed as children.

Bricklayers work with equal loads in each hand and rockblasters also lift their tools and materials with both hands. Thus dexterity may have little significance for work exposures. In the different sport activities dexterity may play a role. To allow for the possible effect of dexterity it was included in all the logistic regression analyses.

\section{Clinical examination}

The clinical examination was carried out without the knowledge of exposure of the investigated person. The participants were examined by the author together with a physiotherapist. The medical history included questions of previous injuries and diseases of the musculoskeletal system. It also contained questions of previous shoulder pain during work in different situations, or at rest. The findings from the examination of the rotator cuff and the biceps muscles were recorded in a protocol and the pain reactions were categorized into one of a three point estimate. Grade 1 represented no pain reaction, grade 2 , moderate pain reaction and grade 3 pronounced pain reaction.

The outcome variable 'signs of shoulder tendinitis' was defined as pronounced palpable pain (grade 3 ) of the muscle attachment or pronounced pain reaction to isometric contraction in any of the four rotator cuff muscles or the biceps muscles.

The clinical investigation included forced passive adduction of each arm in the horizontal shoulder plane which is a frequently used clinical sign of osteoarthrosis of the acromioclavicular joint ${ }^{10}$. Pain reaction to this manoeuvre was recorded as a three point estimate where 1, was no pain; 2 , moderate pain; and 3, represented pronounced pain reaction to the manoeuvre.

\section{Radiography}

Anteroposterior radiographs of the acromioclavicular joints were viewed, approved and categorized by the radiologist and the author into one of five grades of osteoarthrosis according to Collins ${ }^{11}$. The correlation of this morphological grading to the radiographic findings has previously been investigated by Stenlund et al. ${ }^{12}$ and the radiographs were classified accordingly. The grading was as follows: grade 0 , normal; grade 1, minimal changes; grade 2, moderate changes, more severe changes in the cartilage and the bone structure begins to be affected; grade 3, severe osteoarthrosis; grade 4, totally destroyed joint.

Classification was done without knowledge of age, name or reported exposure for the investigated person. For the calculations grades 2 and 3 were combined as osteoarthrosis. No joints of grade 4 classification were found. Grades 0 and 1 were both considered to be a normal joint, since the minimal changes of grade 1 would not have been considered as radiographically verified osteoarthrosis in clinical practice.

Subjects who had reacted with pronounced pain to forced adduction of the arm in the horizontal plane and who had osteoarthrosis of the acromioclavicular joint on the same side at the radiographic examination, were categorized as having clinical and radiographic signs of osteoarthrosis of the acromioclavicular joint.

\section{Data analyses}

The data were analysed in unconditional logistic regression analyses. The background variables of age and dexterity were fitted into the unconditional multiple logistic regression analysis in all models. The job title was entered in the analyses to adjust for work in the analyses of sports. In all logistic regression models, left and right sides were calculated separately.

The analyses were performed using the EPILOG computer program (Epicenter Software, Pasadena, California, USA). Results were presented as relative risks, estimated as odds ratios with confidence intervals. Background variables were presented as means with standard deviation.

\section{Results}

The risk for signs of shoulder tendinitis for those who had been active in sports involving the arms for more than $8399 \mathrm{~h}$ during life, compared with those who reported less than that, was 9.5 on the right side and 4.9 on the left (Table 4). Sport activities classified in 0-5279, 5280-8399 and >8399 $\mathrm{h}$ during life yielded odds ratios of 2.1 on the right side and 1.8 on the left side. In the comparison of the risk for those who had been active $>8399 \mathrm{~h}$ compared with those who belonged to the low-activity group, relative risk estimations for signs of tendinitis were 8.8 on the right side and 4.6 on the left side (Table 4).

The risk for signs of shoulder tendinitis for subjects who indulged in high sports activity (>8399 life hours) and had reported an extremely high exposure to load lifted ( $>26000$ tonnes) were 5.9 on the right side and 10.4 on the left side (Table 5).

The results were similar in the multiple logistic regression models for the radiographic and clinical signs of osteoarthrosis of the acromioclavicular joint. Sport activity of more than $8399 \mathrm{~h}$ yielded odds ratios of 4.6 on the right side and 2.8 on the left side. Sport activities in three classes yielded odds ratios of 1.5 on the right side and 1.3 on the left side. The highest exposure group compared with the lowest yielded an odds ratio of 4.3 on the right side and 2.6 on the left side with wide confidence intervals (Table 6). The relative risk estimations for radiographic and clinical signs of osteoarthrosis in the acromioclavicular joints for the subjects who had high exposure to physical 
Table 4. Unconditional multiple logistic regression of signs of shoulder tendinitis of the right and left shoulder in relation to life-hours of sport (odds ratios)

\begin{tabular}{|c|c|c|c|c|c|c|}
\hline & \multicolumn{2}{|c|}{ Model 1} & \multicolumn{2}{|c|}{ Model 2} & \multicolumn{2}{|c|}{ Model 3} \\
\hline & Right side & Left side & Right side & Left side & Right side & Left side \\
\hline Stratum constant & $\begin{array}{l}0.010 \\
(0.002-0.056)\end{array}$ & $\begin{array}{l}0.014 \\
(0.003-0.069)\end{array}$ & $\begin{array}{l}0.005 \\
(0.001-0.032)\end{array}$ & $\begin{array}{l}0.008 \\
(0.001-0.046)\end{array}$ & $\begin{array}{l}0.010 \\
(0.002-0.058)\end{array}$ & $\begin{array}{l}0.013 \\
(0.003-0.065)\end{array}$ \\
\hline Age $25-39,40-55,56-70$ years old & $\begin{array}{l}3.12 \\
(1.79-5.41)\end{array}$ & $\begin{array}{l}2.44 \\
(1.33-4.48)\end{array}$ & $\begin{array}{l}3.07 \\
(1.78-5.30)\end{array}$ & $\begin{array}{l}2.43 \\
(1.32-4.46)\end{array}$ & $\begin{array}{l}3.07 \\
(1.77-5.35)\end{array}$ & $\begin{array}{l}2.43 \\
(1.31-4.50)\end{array}$ \\
\hline $\begin{array}{l}\text { Dexterity: right-handed versus } \\
\text { left-handed and ambidextrous }\end{array}$ & $\begin{array}{l}1.97 \\
(0.70-5.57)\end{array}$ & $\begin{array}{l}0.51 \\
(0.16-1.67)\end{array}$ & $\begin{array}{l}2.08 \\
(0.74-5.82)\end{array}$ & $\begin{array}{l}0.48 \\
(0.14-1.57)\end{array}$ & $\begin{array}{l}1.93 \\
(0.68-5.50)\end{array}$ & $\begin{array}{l}0.53 \\
(0.16-1.77)\end{array}$ \\
\hline $\begin{array}{l}\text { Job title: bricklayers and } \\
\text { rockblasters versus foremen }\end{array}$ & $\begin{array}{l}1.15 \\
(0.55-2.43)\end{array}$ & $\begin{array}{l}2.28 \\
(0.92-5.62)\end{array}$ & $\begin{array}{l}1.20 \\
(0.57-2.52)\end{array}$ & $\begin{array}{l}2.33 \\
(0.95-5.74)\end{array}$ & $\begin{array}{l}1.29 \\
(0.60-2.75)\end{array}$ & $\begin{array}{l}2.72 \\
(1.06-6.90)\end{array}$ \\
\hline $\begin{array}{l}\text { Sport activity hours }>8399 \\
\text { versus } 0-8399 \mathrm{~h}\end{array}$ & $\begin{array}{l}9.45 \\
(2.09-42.65)\end{array}$ & $\begin{array}{l}4.91 \\
(1.22-19.77)\end{array}$ & - & - & - & - \\
\hline $\begin{array}{l}\text { Sport activity hours } 0-5279,5280- \\
8399,>8399 \mathrm{~h}\end{array}$ & - & - & $\begin{array}{l}2.09 \\
(1.11-3.93)\end{array}$ & $\begin{array}{l}1.80 \\
(0.94-3.46)\end{array}$ & - & - \\
\hline $\begin{array}{l}\text { Sport activity hours }>8399 \mathrm{~h} \\
\text { versus } 0-5279 \mathrm{~h}\end{array}$ & - & - & - & - & $\begin{array}{l}8.83 \\
(1.96-39.86)\end{array}$ & $\begin{array}{l}4.64 \\
(1.14-18.83)\end{array}$ \\
\hline
\end{tabular}

Numbers in parentheses are $95 \%$ confidence intervals

Table 5. Unconditional multiple logistic regression of signs of shoulder tendinitis in relation to physical load from sport activities combined with heavy work (odds ratios)

\begin{tabular}{|c|c|c|}
\hline & Right side & Left side \\
\hline Stratum constant & $0.014(0.003-0.069)$ & $0.020(0.004-0.093)$ \\
\hline $\begin{array}{l}\text { Age: } 25-39,40-55 \\
\text { and } 56-70 \text { years old }\end{array}$ & $3.04(1.79-5.14)$ & $2.62(1.43-4.80)$ \\
\hline Dexterity* & $1.80(0.67-4.85)$ & $0.58(0.18-1.84)$ \\
\hline $\begin{array}{l}\text { The combination of } \\
>8399 \text { sports hours } \\
\text { and }>26000 \text { lifted } \\
\text { tonnes versus all } \\
\text { others }\end{array}$ & $5.94(0.96-36.74)$ & $10.38(1.69-63.81)$ \\
\hline
\end{tabular}

Numbers in parentheses are $95 \%$ confidence intervals

* For the right joint, right-handed were compared with lefthanded and ambidextrous, for the left joint, left-handed and ambidextrous were compared with right-handed load in their working life and at the same time had been extremely active in sports were 12.5 on the right side and 6.7 on the left side. The confidence intervals were, however, wide (Table 7).

\section{Discussion}

Sport activities that involve arm loading seem to be a risk factor for shoulder tendinitis defined as pronounced pain on palpation or pronounced pain reaction to isometric contraction of any of the rotator cuff muscles or the biceps muscles of the shoulders, if the activity has exceeded 8400 life hours. The risk for clinical signs of osteoarthrosis of the acromioclavicular joint in relation to sport activities was also considerably increased. The estimation on the left side was however uncertain. Subjects who reported both extreme sport activity and extremely high

Table 6. Unconditional multiple logistic regression of radiographic and clinical signs of osteoarthrosis of the right and left acromioclavicular joint in relation to life hours of sports

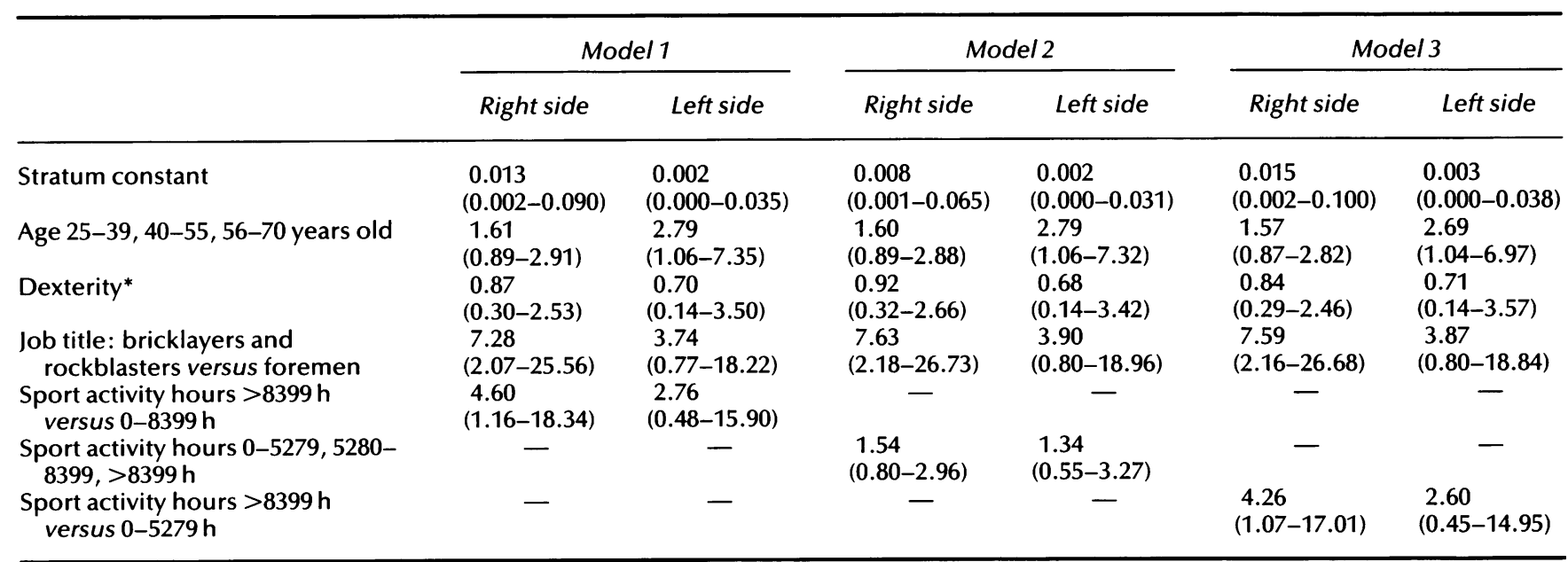

Numbers in parentheses are $95 \%$ confidence intervals

* For the right joint, right-handed were compared with left-handed and ambidextrous, for the left joint, left-handed and ambidextrous were compared with right-handed 
Table 7. Unconditional multiple logistic regression of clinical and radiographic signs of osteoarthrosis in the acromioclavicular joints in relation to physical load from sport activities combined with heavy work

\begin{tabular}{|c|c|c|}
\hline & Right side & Left side \\
\hline Stratum constant & $0.043(0.008-0.227)$ & $0.004(0.000-0.053)$ \\
\hline $\begin{array}{l}\text { Age: } 25-39,40-55 \\
\text { and } 56-70 \text { years old }\end{array}$ & $1.87(1.03-3.41)$ & $3.23(1.21-8.63)$ \\
\hline Dexterity* & $0.75(0.27-2.10)$ & $0.84 \quad(0.17-4.08)$ \\
\hline $\begin{array}{l}\text { The combination of } \\
>8399 \text { sports hours } \\
\text { and }>26000 \text { lifted } \\
\text { tonnes versus all } \\
\text { others }\end{array}$ & $12.49(2.13-73.19)$ & $6.70(1.03-43.64)$ \\
\hline
\end{tabular}

Numbers in parentheses are $95 \%$ confidence intervals * For the right joint, right-handed were compared with lefthanded and ambidextrous, for the left joint, left-handed and ambidextrous were compared with right-handed

physical workload had a high risk of developing osteoarthrosis of the acromioclavicular joint and shoulder tendinitis. The relative risks for individual sports were not possible to calculate since there were so many different sports and too few active in each individual sport to permit analysis.

\section{Selection bias}

A selection bias that may influence the outcome is the possibility that tendinitis of the shoulder or osteoarthrosis of the acromioclavicular joint may make sport activities or heavy manual work impossible. Such selection is possible in this study and would lead to an underestimate of the relative risk since there would be fewer active sports participants or fewer exposed workers available for the study. Among the 98 foremen six had changed from manual work in the construction industry to foremen because of musculoskeletal complaints in the cervical or lumbar spine but only one changed because of shoulder symptoms. This finding might be interpreted as an indication that selection bias arising from manual work is not usual in the construction industry. It does not, however, give any indication of the magnitude of selection bias resulting from sports exposure.

\section{Misclassification of exposure}

In the present study, non-differential misclassification of exposure might have been introduced in the subjective assessments of exposure. With such misclassification the relative risk moves towards unity ${ }^{13}$. Kilbom et al. ${ }^{14}$ demonstrated that $20 \%$ of self-reported lifts did not occur in the workplace and that only $10 \%$ of the workers reported correct weights and frequencies of materials handled. It is obvious that there is some difficulty in remembering how many hours one has spent in sporting activities during the years. There is, however, no indication that the upper $5 \%$ of sports active participants would exaggerate the time they allocated to sport but if so it would diminish a truly increased risk. Classifying the exposure parameters in broad classes was one way of making the exact values in the present study less important.

Age can result in a differential misclassification of exposure assessment since older people in general may have more difficulty in recalling exposure than younger people. This would also diminish a truly increased risk. There was no indication of a differential misclassification of exposure such that subjects with signs of tendinitis or acromioclavicular osteoarthrosis exaggerated their exposure while the subjects without these afflictions did not.

\section{Misclassification of outcome}

The pain reactions to palpation and isometric contraction were each classified into one of three different grades. In the calculations only grade 3 (pronounced pain reaction) was classified as a positive sign of tendinitis or muscle attachment inflammation. The difference between grades 2 and 3 is relatively distinct. Grade 3 was assessed when the insertion was extremely tender and resulted in a recoil reaction, whereas grade 2 represented a moderate reaction to palpation or isometric contraction. Choosing only grade 3 as a relevant sign for tendinitis was one way of reducing misclassification of outcome.

Osteoarthrosis of the acromioclavicular joint was classified according to Collins ${ }^{11}$ into one of five different grades. In the calculations, grades 0 and 1 were combined as no osteoarthrosis and grades 2 and 3 were combined as osteoarthrosis. The difference between grades 1 and 2 is relatively distinct. In order to minimize the risk of misclassification all radiographs were graded by the author and a radiologist in one session.

\section{Confounding}

Age is a possible confounding variable and was included in all the multiple logistic regression models. Smoking and dexterity were first entered in all models but smoking was removed from the models since it did not have confounder properties.

Manual work has previously been demonstrated to have an influence on the development of osteoarthrosis of the acromioclavicular joint and on tendinitis of the shoulder ${ }^{8,9}$. Sport activities were furthermore unevenly distributed among the three job titles (Table 7), hence job title had confounder properties and was entered in all regression models.

\section{External validity}

There are a few studies that have been published on osteoarthrosis of the hip in relation to sports ${ }^{15-17}$ and one of them also reports on sports in relation to osteoarthrosis of the knee joint ${ }^{15}$ but none of these studies has evaluated the exposure to sports in terms of time. In a study by Vingård and co-workers ${ }^{18}$, however, long-term sport activities were studied in 233 men with osteoarthrosis of the hip and recent hip prosthesis replacement. These men were compared to a group of 302 randomly selected men and 
evaluated with reference to long-term exposure to sports. Men with high exposure to sports were found to have a relative risk of osteoarthrosis of the hip of 4.5 compared to the group with low exposure. The findings of a higher risk for osteoarthrosis in the acromioclavicular joint for subjects who have been extremely active in sports in the present study is consistent with these findings. Vingård and coworkers also found that men who had been exposed to high physical load from occupation and sports had an even higher relative risk $(R R=8.5)$ of developing osteoarthrosis of the hip ${ }^{18}$. In the present study a similar pattern of high odds ratios was demonstrated for osteoarthrosis of the acromioclavicular joint as well as for shoulder tendinitis as a result of the combination of extreme sport activities and extreme load lifted.

Shoulder tendinitis and its relation to sports has previously been reported in the literature. Kennedy and Hawkins ${ }^{1}$ have reported on swimmer's shoulder and several authors have reported on baseball pitching and other sport activities as causes of injury to the shoulder muscles and tendons ${ }^{2-6}$ but epidemiological methods have previously not been used in risk evaluation of sports related to different musculoskeletal complaints in the shoulders.

In the analyses of osteoarthrosis of the acromioclavicular joint, job title had higher odds ratios than sport activity. This finding indicates that the working factor might be of greater importance for the development of osteoarthrosis than sport activities. A possible reason for this is that the work tasks contain vibration exposure and more static loading.

In the analyses of signs of tendinitis, job title yielded lower odds ratios than sport activities. A possible explanation of this finding is that high exposure to sports of this magnitude $(>8399 \mathrm{~h})$ is in fact more hazardous to the shoulder muscles than work as a bricklayer or a rockblaster.

Long-term sport activities that involve arm loads seem to be hazardous to the rotator cuff muscles, the biceps muscles and the acromioclavicular joints. Furthermore the combination of high physical work load and extremely high sport activity seems to be an even greater risk for clinical signs of osteoarthrosis of the acromioclavicular joint and for signs of shoulder tendinitis.

\section{Acknowledgements}

This study was supported by grants from the Swedish Labour Market Insurance Company, AFA and the Research Foundation of
Bygghälsan. I would like to thank Professors Ian Goldie, Christer Hogstedt, Mats Hagberg and Olle Marions for their valuable help. I would also like to thank Barbro Olofsson and Staffan Norlander for their help with data collection.

\section{References}

1 Kennedy JC, Hawkins RJ. Swimmer's shoulder. Physician and Sportsmedicine 1974; 2: 35-8.

2 Jobe FW, Tibone JE, Perry J, Moynes D. An EMG analysis of the shoulder in throwing and pitching. A preliminary report. Am J Sports Med 1983; 11: 3-5.

3 Lehman R. Shoulder pain in the competitive tennis player. Clin Sports Med 1988; 7: 309-27.

4 Lo YPC, Hsu YCS, Chan KM. Epidemiology of shoulder impingement in upper arm sports events. Br J Sports Med 1990; 24: 173-7.

5 Nevasier T. Weight lifting. Risks and injuries to the shoulder. Clin Sports Med 1991; 10: 615-21.

6 Nirschl R. Prevention and treatment of elbow and shoulder injuries in the tennis player. Clin Sports Med 1988; 7: 289-308.

7 Hagberg M, Wegman DH. Prevalence rates and odds ratios of shoulder neck diseases in different occupational groups. $\mathrm{Br} J$ Ind Med 1987; 44: 602-10.

8 Stenlund B, Goldie I, Hagberg M, Hogstedt C. Shoulder tendinitis and the relation to heavy manual work and exposure to vibration. Scandinavian Journal of Work Environment and Health 1993; 19: 43-9.

9 Stenlund B, Goldie I, Hagberg M, Hogstedt C, Marions O. Radiographic osteoarthrosis in the acromioclavicular joint resulting from manual work or exposure to vibration. $\mathrm{Br} J$ Ind Med 1992; 49: 388-93.

10 Waris P, Kourinka I, Kurpa Ket al. Epidemiologic screening of occupational neck and upper limb disorders. Scandinavian Journal of Work Environment and Health 1979; 5(Suppl 3): 25-38.

11 Collins DH. The Pathology of Articular and Spinal Diseases. Liverpool, UK: Edward Arnold, 1950: 74.

12 Stenlund B, Marions O, Engström KF, Goldie I. Correlation of macroscopic osteoarthritic changes and radiographic findings in the acromioclavicular joint. Acta Radiol 1988; 29: 571-6.

13 Flegal KM, Brownie C, Haas JD. The effects of exposure misclassification on estimates of the relative risk. $A m J$ Epidemiol 1986; 123: 736-51.

14 Kilbom $\AA$, Liew M, Lagerlöf E, Broberg E. An ergonomic study of notified cases of occupational musculoskeletal disease. Arbete och Hälsa 1984; 45: 1-51 (in Swedish).

15 Klünder KB, Rud B, Hansen J. Osteoarthritis of the hip and knee joint in retired football players. Acta Orthop Scand 1980; 51: 925-7.

16 Marti B, Knobloch M, Tschopp A, Jucker A, Howald H. Is excessive running predictive of degenerative hip disease? Controlled study of former elite athletes. Br Med J 1989; 299: 91-3.

17 Puranen JK, Ala-Keltoola L, Peltokallio P, Saarela J. Running and primary osteoarthrosis of the hip. $\mathrm{Br}$ Med J 1975; 285: 424-5.

18 Vingård, E, Alfredsson L, Goldie I, Hogstedt C. Sports and osteoarthrosis of the hip, an epidemiological study. Am J Sports Med 1993; 2: 195-200. 